\title{
EDITORIAL
}

\section{EBOLA VIRUS DISEASE: FROM DISASTER TO CONTAINMENT}

In August 26, 1976 in Yambuku, a town in the north of Zaïre, A 44-year-old school teacher returned from a small hike. $\mathrm{H}$ e developed high fever and physician gave him a quinine shot as malaria is commonest there. A week later, he had uncontrolled vomiting, bloody diarrhea, trouble breathing and then bleeding from his nose, mouth, and anus. He died $\sim 14$ days after the onset of symptoms. He started an epidemic known as Ebola virus disease (EVD) that killed 280 of the 313 infected persons $(88 \%)^{1}$

The ebola virus is currently the most important topic around the world due to its serious infectivity and death in latest outbreak in west Africa. Although the latest outbreak started in guinea in December 2013, the quick expansion to surrounding country including Liberia, Sierra leone and Nigeria makes a threat to world health community around March 2014. Since then the EVD including the deadly haemorrhagic manifestation happens among 23218 western African residents (laboratory confirmed 14088) and leads to 9365 deaths. ${ }^{2,3}$ WHO published the case definition within March as suspected, probable and confirmed cases and also declared emergency in countries where the death toll was raising from middle of the year 2014. WHO declared medical emergency of international concerned in later half of the year 2014. The affected country started tackling the situation with help from WHO and all other international alliances. Prevention strategy and infection control measurement were highlighted the control measurement although the poor infrastructure of Western Africa makes the situation worse to fatal.

The imported cases started to make different countries eyebrow raise very soon. The previous countries having 34 imported cases with 15 death were Nigeria, Senegal, USA, Spain and Mali were affected. The latest country with a single confirmed case is United Kingdom. Now in February 2015 there are currently no cases of Ebola virus disease (EVD) in Senegal, Nigeria, Spain, the United States, and Mali. A country is considered to be free of Ebola virus transmission when 42 days (double the 21-day incubation period of the Ebola virus) has elapsed since the last patient in isolation became laboratory negative for EVD. ${ }^{2,3}$ The true numbers of cases and deaths are certainly higher. There are numerous reports of symptomatic persons evading diagnosis and treatment, of laboratory diagnoses that have not been included in national databases, and of persons with suspected EVD who were buried without a diagnosis having been made ${ }^{4}$.

Virologic investigation identified Zaire ebolavirus (EBOV) as the causative agent. Full-length genome sequencing and phylogenetic analysis showed that EBOV from Guinea forms a separate clade in relationship to the known EBOV strains from the Democratic Republic of Congo and Gabon. ${ }^{5}$ Epidemiologic investigation linked the laboratoryconfirmed cases with the presumed first fatality of the outbreak in December 2013. This study demonstrates the emergence of a new EBOV strain in Guinea. ${ }^{6}$ Since 1976, three ebolavirus species have caused outbreaks in sub-Saharan Africa: EBOV, Sudan ebolavirus, and the recently described Bundibugyo ebolavirus. ${ }^{6,7}$ Epidemics have occurred in the Democratic Republic of Congo, Sudan, Gabon, Republic of Congo, and Uganda. Reston ebolavirus which circulates in the Philippines. And found to has caused disease in nonhuman primates but not in humans. ${ }^{8}$ The fifth species, Tai Forest ebolavirus, was documented in a single human infection caused by contact with an infected chimpanzee from the Tai Forest in Ivory Coast. ${ }^{9}$

The Ebola virus is under family of filovirade with morphology under electron microscope is Filamentous, enveloped RNA virus ,approx. $19 \mathrm{~kb}$ in length ( $1 \mathrm{~kb}=1000$ RNA bases/nucleotides) or 60$80 \mathrm{~nm}$ in diameter, Single-stranded, linear, nonsegmented negative-sense RNA (encoded in a 3' to 5' direction) and appears to have "spikes" due to glycoprotein on outside membrane ${ }^{8}$. The virus characteristics are consistent with clinical syndrome of viral haemorrhagic fever disease who can presented with fever, headache, joint and muscle aches, weakness, diarrhoea, vomitting, stomach pain, lack of appetite, and unexplained bleeding. The Incubation period ranges from 2-21 days. The interest grows on host from where the disease extends. The initial 
interest was grown in gorilla and chimpanzees as human disaster in outbreaks were concomitantly associated with wild animal fatality.

The virus kills gorillas and chimpanzees and other monkeys. Because it kills apes in such high percentage that they are not likely to be its natural host. ${ }^{10}$ Three trapping expeditions in areas close to infected gorilla and chimpanzee carcasses in Gabon and in Congo were done 1,030 animals were tested including 679 bats, 222 birds and 129 small terrestrial vertebrates (PCR). Later Viral nucleotides were discovered in 3 species of bats. 10

The current outbreaks has laid to fear in different countries as sporadic cases imported to developed country and health care providers were found to be the more vulnerable starting from death of Dr Khan, the legendary physician of EVD of Sierre leone to the volunteer of America. The volunteer nurse in spain leads to even huge impact of health care system vulnerability as protest were raising quickly. The incidence as the seriousness was tackled appropriately with the recommendation of every country to be prepared for emergent ebola virus in their own soil. In the absence of any vaccine or cure, the advice for this outbreak is much the same as it was in the 1970s. "Soap, gloves, isolating patients, not reusing needles and quarantining the contacts of those who are ill - in theory it should be very easy to contain Ebola. We shouldn't forget that this is a disease of poverty, of dysfunctional health systems and of distrust," says Piot. ${ }^{11}$ In March, Liberia's health minister advised people to stop having sex, in addition to existing advice not to shake hands or kiss. The WHO says men can still transmit the virus through their semen for up to seven weeks after recovering from Ebola."

Direct contact with bodily fluids of a person who is sick with or has died from Ebola (blood, vomit, urinbe, stool, sweet, semen, spit, other fluids), Objects contaminated with the virus (needles, medical equipment) and infected animals (by contact with blood or fluids or infected meat) are the mainstay of transmission which is alarming but at the same time not to be disasterous as it is not transmitted through air, through contaminated food and water and not from asymptomatic individuals (Ebola only spreads when people are sick).

Symptoms may appear anywhere from 2 to 21 days after exposure to ebola virus though 8-10 days is most common. Some who become sick with Ebola HF are able to recover, while others do not. The reasons behind this are not yet fully understood. However, it is known that patients who die usually have not developed a significant immune response to the virus at the time of death. Hospitalization increased survival in patients of EVD than in nonhospitalized persons were the observation in recent outbreak. This is more likely due to detection of cases if they were fatal, or that some persons died before they could be admitted to the hospital. In each of the countries studied, the case fatality rate is lowest among persons 15 to 44 year of age, and highest among persons 45 years of age or older, and among health care workers was observed among countries.

As there is no approved drugs for EVD, Supportive care like fluids and electrolytes balance, Maintaining oxygen status and BP and treatment of complicating infections is the mainstay of management. The amount of fluid need is huge and even more than 15 to 16 litres of fluids should be given to patient with severe prostration and dehydration. Experimental treatments like ZMapp by Mapp Biopharmaceutical Inc, USA were approved by the scientist in severe cases as the USA cases were found to be benefited apparently with the drug. ${ }^{12}$ A combination of 3 monoclonal antibodies that bind to the protein of Ebola virus( Not yet been tested in humans; requires RCTs for safety and effectiveness) and 2 US patients in Liberia received treatment and showed improvement is encouraging but need scientific evidence of trials before recommendation. Currently there is no FDA approved vaccines for EBD. Experimental vaccines are in progres with the NIH is working on developing an Ebola/Marburg vaccine. A candidate Ebola vaccine based on rabies vaccine is in Phase 1 vaccine trials.

For stopping the ebola outbreak the five principles that follows were a.Finding Ebola cases, b.Isolation and patient care, c.Contact tracing to stop the chains of transmission, d. Safe burial practices, e. Strict infection control measures in hospitals by health care workers. The airport measurement in Africa and all other countries were variable from time to time with importance of screening the symptomatic patients. The health care providers were given instructions for barrier nursing techniques, wearing of protective clothing (such as masks, gloves, gowns, and goggles), The use of infection-control measures (such as complete equipment sterilization and routine use of disinfectant and isolation of Ebola HF patients from contact with unprotected persons were the crucial steps by which the disease started to contained not only in developed country but also in western Africa. Currently the three countries with highest mortality of EBD is also now settles with the hope of complete containment in near future. 
In Bangladesh early measurement were taken appropriately by health ministry. The procedures undertaken were active screening of passangers from West Africa nations for Ebola symptoms. An special isolation unit was established in Kurmitola General Hospital with 20 beds and trained appropriately equipped and staffed to handle Ebola cases were generated. EBD guideline for management and infection control measures including burial practice were prepared .Protocols are put in place to protect against further spread of disease and preparedness and response with posters, banners, Illustrations, brochures were prepared. But still the risk of getting EBD is possible in Bangladesh due to over interconnected world and Peace keepers posted in West Africa - approx. 800 and we do not have facilities to test Ebola. The strength of Bangladesh is we already have emergency prepraedness plan running due to our previous planning for Middle-East Respiratory Syndrome (MERS) Coronavirus, Nipah virus and Pandemic influenza

Sheikh Umar khan, the unfortunate legends of EBD in Sierre leon said"Health workers are prone to the disease because we are the first port of call for those with the disease. Even with the full kit we put on we're at risk."'I'm afraid for my life, because I cherish my life. And if you are afraid then you must take the maximum precautions, stay vigilant and stay on your guard" . The health professionals must be cautious, courageous, knowledgeable and prepared to deal with the infection control measurement against EVD. The deadly virus can mutate and potential outbreaks are always on card. The disaster scenario to combating phenomena in current outbreak was not flawless but the experience leads to believe that appropriate prevention strategy and infection control measurement can curtail the worst virus the world has recently experienced.

Quazi Tarikul Islam', Md Robed Amin ${ }^{2}$

${ }^{1}$ Prof of Medicine, Popular Medical College, 1Associate Professor of Medicine, Dhaka Medical College

\section{References:}

1. Ebola haemorrhagic fever in Zaire, 1976. Bull World Health Organ 1978;56:271-93.

2. Global alert and response: Ebola virus disease. Geneva: World Health Organization, 2014 (http:// www.who.int/csr/don/ archive/disease/ ebola/en).

3. Ebola response roadmap situation report. Geneva: World Health Organization, 2014 (http:// apps.who.int/iris/bitstream/10665/137510/1/ roadmapsitrep_5Nov14 eng.pdf?ua-1).

4. Sylvain Baize., Delphine Pannetie., Lisa Oestereich.et al. Emergence of Zaire Ebola Virus Disease in Guinea. N Engl J Med 2014;371:141825.

5. Feldmann H, Sanchez A, Geisbert TW. Filoviridae: Marburg and Ebola viruses. In: Knipe DM, Howley PM, eds. Fields virology. 6th ed. Philadelphia: Lippincott Williams \& Wilkins, 2013:923-56.

6. Feldmann H, Geisbert TW. Ebola haemorrhagic fever. Lancet 2011;377:849- 62.

7. Hartman AL, Towner JS, Nichol ST. Ebola and Marburg hemorrhagic fever. Clin Lab Med 2010;30:161-77.

8. Miranda ME, Ksiazek TG, Retuya TJ, et al. Epidemiology of Ebola (subtypeReston) virus in the Philippines, 1996.J Infect Dis 1999;179:Supp1 1:S115-S119.

9. Formenty P, Hatz C, Le Guenno B, Stoll A, Rogenmoser P, Widmer A. Human infection due to Ebola virus, subtype C.ted'Ivoire: clinical and biologic presentation. J Infect Dis 1999;179:Supp1 $1: \mathrm{S} 48-\mathrm{S} 53$.

10. Sanchez A, Ksiazek TG, Rollin PE, et al. Detection and molecular characterization of Ebola viruses causing disease in human and nonhuman primates. J Infect Dis 1999;179:Suppl 1:S164-S169.

11. http://www.bbc.com/news/magazine-28262541

12. Qiu X, Wong G, Audet J, et al. Reversion of advanced Ebola virus disease in nonhuman primates with ZMapp. Nature 2014;514:47-53. 